\title{
Perancangan Sistem Informasi Pendataan Alat Tulis Kantor Berbasis Web pada Fakultas Ekonomi dan Bisnis Islam UIN Raden Fatah Palembang
}

\author{
Dwi Mardiana ${ }^{1 *}$ \\ ${ }^{1}$ UIN Raden Fatah Palembang, Indonesia
}

\begin{abstract}
Abstrak: Penelitian ini bertujuan untuk menghasilkan sebuah rancangan interface untuk membangun sistem pendataan alat tulis kantor. Metode penelitian yang digunakan adalah deskriptif. Dalam penelitian ini sistem berjalan digambarkan dalam bentuk workflow diagram dan arus informasi sistem pendataan ATK yang telah dibuat digambarkan dalam bentuk data flow diagram (DFD). Penelitian ini menghasilkan rancangan interface sistem berdasarkan proses-proses yang telah diusulkan yang nantinya dapat diterapkan pada Fakultas Ekonomi dan Bisnis Islam.
\end{abstract}

Kata Kunci: Pendataan, Alat Tulis Kantor, Sistem Informasi, Web

\begin{abstract}
This study aims to produce an interface design to build an office stationery data collection system. The research method used is descriptive. In this study, the running system is described in the form of a workflow diagram and the information flow of the ATK data collection system that has been created is described in the form of a data flow diagram (DFD). This research produces a system interface design based on the processes that have been proposed which can later be applied to the Faculty of Islamic Economics and Business.
\end{abstract}

Keywords: Data Collection, Office Stationery, Information System, Web

\section{Pendahuluan}

Perkembangan teknologi beberapa tahun terakhir sangatlah pesat. Dimana kehidupan manusia di zaman sekarang ini tidak lepas dari kemajuan teknologi. Salah satu manfaat dari kemajuan teknologi yakni dapat memudahkan pekerjaan manusia. Contoh teknologi yang sering digunakan diera sekarang seperti komputer, laptop, handphone dan lainnya. Kemajuan teknologi bagi manusia mempunyai dampak positif seperti memudahkan untuk memperoleh informasi, pekerjaan yang dapat dilakukan secara efektif dan efisien, pertukaran informasi yang lebih mudah dan cepat, dan dapat melakukan pembelajaran secara daring/online tanpa harus tatap muka langsung.

Fakultas Ekonomi dan Bisnis Islam merupakan salah satu fakultas yang ada di Universitas Islam Negeri Raden Fatah Palembang dengan mahasiswa terbanyak setelah fakulas Tarbiyah dan Keguruan. Beberapa kegiatan telah menggunakan sistem informasi yang saling terintegrasi. Kegiatan perkantoran sangatlah identik dengan berbagai peralatan atau kebutuhan yang diperlukan (Darmawan \& Fauzi, 2016). Kegiatan operasional perkantoran dapat berjalan dengan lancar salah satunya bila kersediaan barang alat tulis

\footnotetext{
${ }^{*}$ Corresponding Author: Dwi Mardiana (dwimardiana_uin@radenfatah.ac.id). UIN Raden Fatah Palembang, Indonesia
} 
kantor yang mencukupi untuk kegiatan operasional perkantoran. Barang alat tulis kantor seperti kertas, pena, catrigh, lem, dan lainnya harus terdata dengan rapi agar pelaporan pengeluaran barang dan masuk terdata dengan baik. Dilakukan pengelolaan yang baik supaya tidak menimbulkan pemborosan yang nantinya akan mengakibatkan pemborosan dan akan berimbas kekurangan alat tulis kantor. Terkadang kebutuhan alat tulis kantor yang mendadak harus diadakan agar lancar seluruh kegiatan yang dikerjakan. Alat tulis kantor (ATK) adalah benda-benda yang dipakai habis dalam pelaksanaan dalam pekerjaan sehari-hari dari pegawai-pegawai tata usaha (Julianti et al., 2019).

Pendataan barang alat tulis kantor di Fakultas Ekonomi dan Bisnis Islam sekarang berjalan secara manual. Persediaan diperlukan untuk menjaga kelancaran operasi dalam sebuah perusahaan (Aryanto \& Winarso, 2016). Untuk mengetahui stok barang masih tersedia atau tidaknya harus dilihat dalam Microsoft Excel atau melihat langsung dalam ruangan penyimpanan stok barang yang tersedia. Permintaan barang oleh karyawan juga masing menggunakan cara manual yakni menggunakan Form yang ditulis tangan dan diajukan kepada petugas. Pelaporan data barang masuk dan keluar dilakukan dengan manual dan belum terintegrasi antar karyawan yang terkait. Pelaporan data yang lambat dikarenakan harus mendata seluruh barang masuk dan keluar dengan selesai. Dan hal ini kurang efektif untuk dijalankan dalam kegiatan sehari-hari dan perlu adanya solusi agar seluruh kegiatan dalam pendataan alat tulis kantor berjalan dengan lancar tanpa adanya proses yang lambat (Darmawan \& Fauzi, 2016).

\section{Metode Penelitian}

Dalam penelitian ini metode yang digunakan yaitu metode deskriptif. Objek penelitian dilakukan pada Fakultas Ekonomi dan Bisnis Islam UIN
Raden Fatah Palembang. Adapun penelitian ini dilakukan untuk mengetahui bagaimana proses pendataan alat tulis kantor pada pada Fakultas Ekonomi dan Bisnis Islam UIN Raden Fatah Palembang. Pengumpulan data dilakukan melalui observasi. Dalam penelitian ini sistem berjalan digambarkan dalam bentuk workflow diagram dan arus informasi sistem pendataan ATK yang telah dibuat digambarkan dalam bentuk data flow diagram (DFD). DFD dapat menggambarkan arus data di dalam sistem dengan terstruktur dan jelas. Beberapa simbol yang digunakan di DFD di antaranya external entity (kesatuan luar) atau boundary (batas sistem), data flow (arus data), process (proses), dan data store (simpanan data).

\section{Hasil Penelitian}

\section{Perancangan Sistem yang Diusulkan}

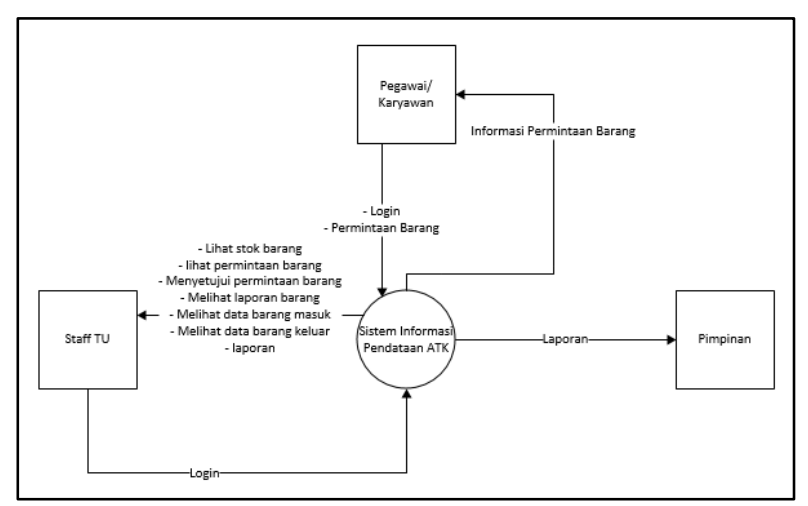

Gambar 1. Sistem yang diusulkan

Dari gambar 1, sistem yang diusulkan menggambarkan adanya 3 entitas yakni Staf TU, Pegawai/Karyawan dan Pimpinan. Staf TU dapat melakukan login ke sistem dan dari sistem Staf TU dapat melihat stok barang, melakukan permintaan barang, menyetujui permintaan barang, melihat data barang masuk dan keluar serta dapat mencetak laporan. Pegawai/karyawan dapat login dan melakukan permintaan barang ke sistem dan dari sistem pegawai/karyawan dapat melihat informasi 
permintaan barang. Pimpinan dapat melihat/cetak laporan dari sistem.

\section{Pembahasan}

Desain sistem bertujuan untuk memberikan gambaran secara umum kepada user tentang sistem yang baru (Wahana \& Riswaya, 2013). Perancangan berikut ini yakni perancangan atau design yang diusulkan. Terdapat 5 halaman interface yang diusulkan.

\section{Halaman Utama (Home)}

Halaman utama yakni tampilan awal ketika mengakses sistem informasi pendataan ATK. Halaman utama terdapat menu Home, Profil dan login.

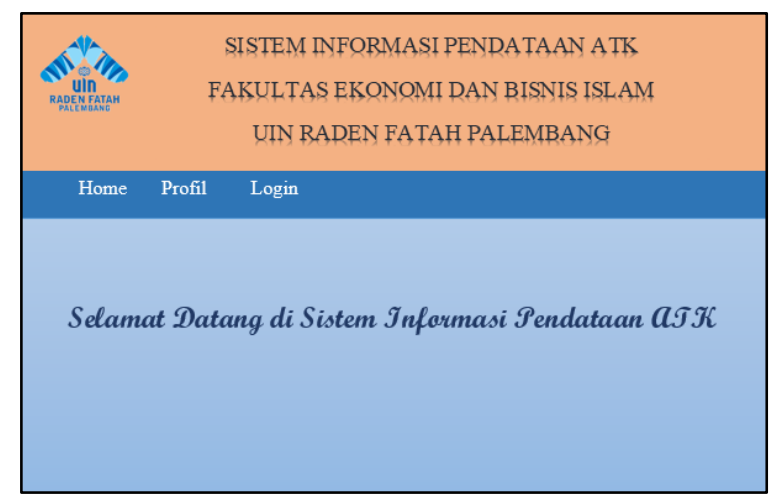

Gambar 2. Halaman Utama (Home)

\section{Form Login}

Halaman Login yakni tampilan yang digunakan untuk login user baik pegawai/karyawan, staf TU serta pimpinan. User login dengan menginputkan username dan password.

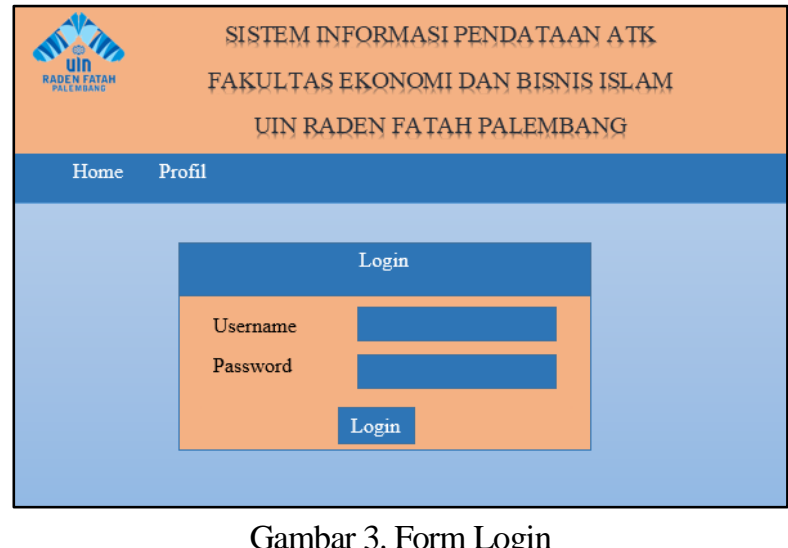

\section{Halaman Stok Barang}

Halaman stok yakni tampilan yang menampilkan kesediaan stok barang ATK. Atribut yang ditampilkan dari halaman ini yakni no, kode ATK, nama ATK, stok dan satuan barang.

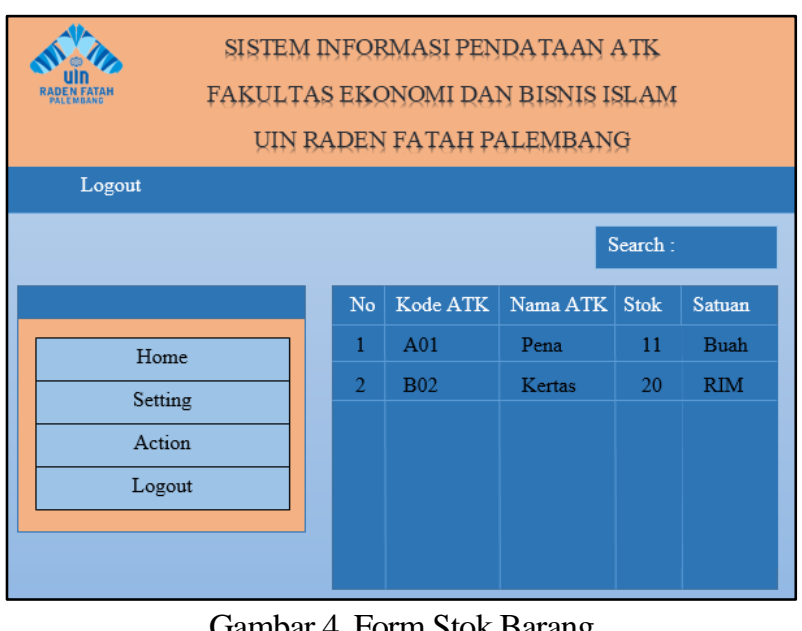

4. Halaman Permintaan ATK

Halaman permintaan ATK yakni tampilan yang menampilkan permintaan ATK. Adapun atribut dari halaman ini no ATK, nama ATK, banyak barang permintaan serta satuan barang 


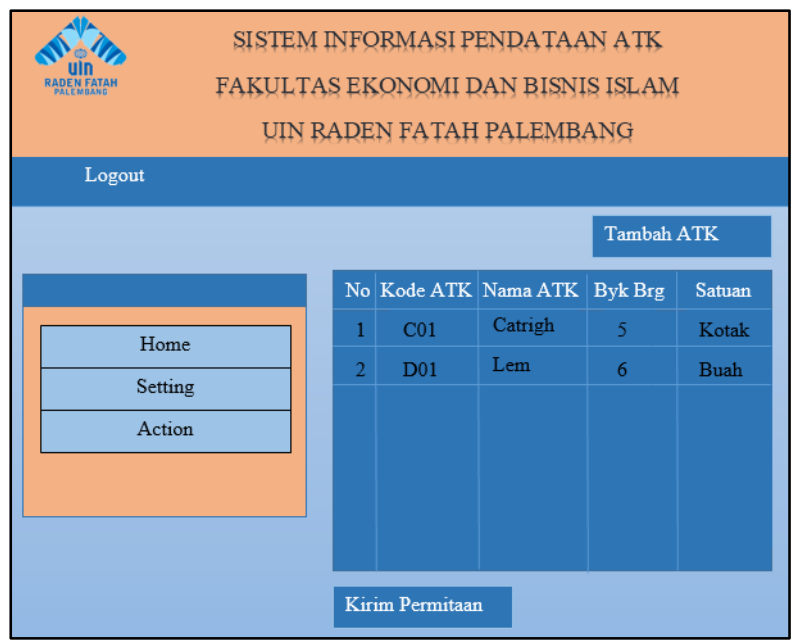

Gambar 5. Form Permintaan ATK

5. Halaman Administrator Staf TU

Halaman ini berisi kegiatan /aktivitas yang akan dikelola oleh staf TU. Adapun kegiatan yang akan dikelola oleh staf TU menu Data ATK, Data User, Data Permintaan dan Laporan.

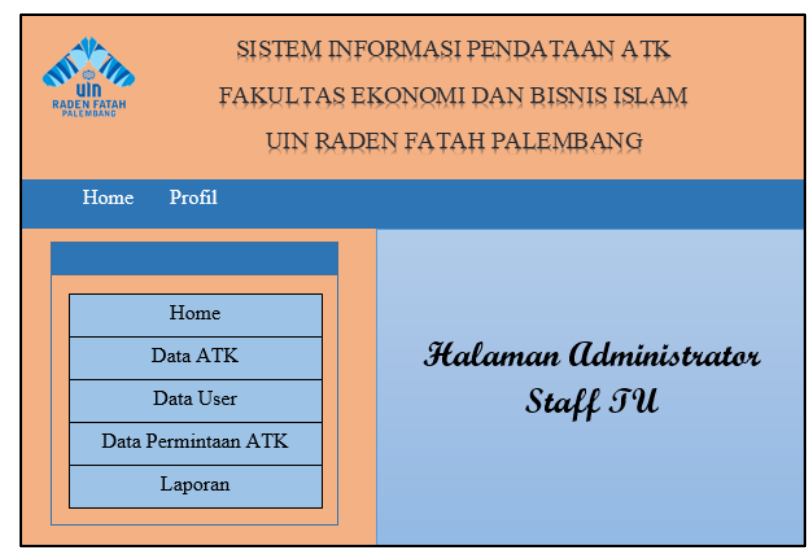

Gambar 6. Halaman Administrator Staf TU

\section{Kesimpulan}

Penelitian ini menyimpulkan bahwa pertama, sistem informasi pendataan ATK dalam penelitian ini menghasilkan 3 entitas yang akan menggunakan sistem yakni Staf TU, Pegawai/Karyawan dan Pimpinan. Proses yang dapat dilakukan oleh ketiga entitas tersebut yakni Login, penginputan barang ATK, stok ATK, Permintaan ATK, serta adanya pembuatan laporan secara berkala. Dan kedua, desain perancangan interface sistem yang telah dibuat dapat menggambarkan proses-proses yang nantinya akan dijalankan oleh tiap-tiap entitas serta DFD yang telah dibuat akan memberikan gambaran alur proses dalam sistem.

\section{Daftar Pustaka}

Aryanto, \& Winarso, D. (2016). Sistem Informasi Persediaan Alat Tulis Kantor Studi Kasus Pada PT Bank Muamalat Indonesia Cabang Pekanbaru. Jurnal Fasilkom, 5(2), 30-38.

Darmawan, D., \& Fauzi, K. N. (2016). Sistem Informasi Manajemen. PT Remaja Rosdakarya.

Julianti, M. R., Dzulhaq, M. I., \& Subroto, A. (2019). Sistem Informasi Pendataan Alat Tulis Kantor Berbasis Web pada PT Astari Niagara Internasional. Jurnal Sisfotek Global, 9(2), 92-97.

Wahana, A., \& Riswaya, A. R. (2013). Sistem Informasi Pengadaan Barang ATK di PT. Mekar Cipta Indah Menggunakan PHP dan MYSQL. Jurnal Computech \& Bisnis, 7(Vol 7, No 2 (2013): Vol. 7 No. 2 Desember 2013), $73-83$. 